resions as upper currents, descend to the surface of the globe on the equatorial side of $30^{\circ}$ of lat. in both hemispheres, they then travel onwards towards the belt of equatorial calms, when they meet and ascend into the upper regions of the atmosphere, whence they travel back towards the poles as upper currents, until they arrive at the calm belis of Caucer and of Capricorn, on the polar sides of which they once more descend to the surface, and are then known as the westerly winds of the temperate zones. Owing to the rotatory motion of the earth, it is impossible for these westerly winds to blow direct towards the poles, but it is clear that if you surround the Polar regions with a belt of westerly winds, that no matter what the direction of the wind may be in the Polar regions, it must, if a surface wind, be supplied by this zone ; and that the winds experienced in the Polar regions are winds travelling on the surface, and are drawn from this belt of warm winds, is, I think, proved by the following extract from an account of the wintering of the Hecla, Capt. (Sir Edward) Parry, at Melville Island, in the year 1819-20:-

"A gale of wind, from whatever quarter it might blow, was almost invariably found to raise the thermometer several degrees, even when it came from the north, as much as $14^{\circ}$. An east, south-east, or east-south-east wind causes the thermometer to rise $40^{\circ} . "$

From this extract it is evident, as might be supposed, that any current of air from this zone or belt of warm westerly winds raised the thermometer considerably, but that the wind that proceeded the more directly from the ocean and had the least land to traverse was the warmest.

Maury, without attempting to prove his case, and indeed throwing the onus of proof on those who ventured to disagree with him, considers that the south-east trade winds of the southern hemisphere become the south-west winds of the north temperate zone, and vice versâ; that the north-east trades of the northern hemisphere become the north-west winds of the south temperate zone. I do not say that this is not the case, but if you admit that the north-east and south-east trade winds meet in the belt of equatorial calns and there ascend, it appears to be more reason. able to suppose that their currerits intermingle and that their mixed volume is then drawn off north and south as required to restore the equilibrium of the atmosphere. And there is a very strong argument against Maury's hypothesis, viz., that as the south-east irades of the southern hemisphere are stronger and extend over a gieater surface than the incrth-east trades of the northern hemisphere, and as also the north-west winds of the southern hemisphere are stronger and more continuous than the south-west winds of the northern hemisphere, it is illogical to suppose that the stronger polar current, i.e., the south-east trade, feeds the weaker equatorial current, i.e., the south-west winds of the north temperate zone; it would be more reasonable to suppose the reverse to be the case.

This entire theory of atmospheric currents is antagonistic to the presumption that a larger body of vapour is carried from the northern to the southern hemisphere.

Owing to the scarcity of land, and especially of very high land in the south temperate zone, not only is the precipitation less, but the vapour-carrying winds, $i . e$, the westerly winds, are far more constant in their direction and force than are the westerly winds of the northern hemisphere. (The proportion of westerly winds to any others in the temperate zone in the North Atlantic is two to one, while throughout the south temperate zone they are so constant as to have been christened by Maury the northwest trades.)

If you once admit that these westerly winds are equatorial currents flowing towards the poles (a fact susceptible of undoubted proof), it is easy enough to account for the low barometer in the Antarctic regions, as also the larger amount of precipitation there as compared with the precipitation in the Arctic regions.

I. Because the westerly winds being much stronger and more continuous in the southern than in the northern hemisphere, the ascension of the air in the South Polar regions must be greater than in the North Polar regions.

2. Because, owing to the westerly winds of the south tem. perate zone parting with less of their moisture (as previously accounted for) than the corresponding winds of the north tem. perate zone, and aiso to their being stronger and more continuous, it is evident that when they meet with Antarctic cold and their vapour is condensed, the precipitation must be greater, which also involves the giving out of a much larger amount of latent heat and the consequent greater expansion and ascension of the atmosphere in the South Polar reyions.

It is, I believe, universally acknowledged that all winds must blow from a high to a low barometer, i.e., from a zone of high pressure to a zone of low pressure (not directly, but in a direction modified by the earth's rotatory motion). I may therefore fairly argue that the zones of low pressure at both the equator and the poles proceed from the same causes, i.e. from precipitation, and from the ascension of the atmosphere, and that the lower barometer in the South Polar regions fairly accounts for the greater strength and continuity of the westerly winds of the south temperate zone, and that without these constant inequalities of pressure we should have neither trades nor westerly winds.

I have purposely from want of space avoided speaking otherwise than generally of the effect of the land on atmospheric currents, nor is it directly pertinent to my present argument.

The hypothesis of atmospheric circulation which $I$ have very briefly sketched is in many of its features susceptible of absolute proof, more especially in the following points, viz. -

I. That the trade-winds descend to the surface of the ocean on the equatorial sides of the calms of Cancer and of Capricorn.

2. That the trade-winds ascend in the belt of equatorial calms.

3. That currents flow from the equator in the upper regions of the atmosphere in an opposite direction to that of the trade-winds on the surface of the ocean.

4. That these upper currents, flowing from the equator, descend again to the surface of the ocean on the polar sides of the calms of Cancer and of Capricorn.

5. That these equatorial currents, subsequent to their descent on the polar sides of the calms of Cancer and of Capricorn, are known as the westerly winds of the temperate zones.

And with reference to my supposition that these westerly winds ascend in the Polar regions, one strong evidence in favour of this is, that if, as I say, the ascension of the atmosphere is greater in the South Polar than in the North Polar regions, the counter or return current towaris the equator must also be greater, which is the fact.

The onus lies on the promoters of the new hypothesis either to reconcile their views with the existing theory of atmospheric circulation or to supply us with a better theory, and one which shall agree equally wrell with well-established facts.

October 27

Digby Murray

\section{Definiteness and Accuracy}

IN my lecture on Force (anté, Sept. 2r), I take for granted that the scientific use of the word is that with which all are familiar in the expression "the para!lelogram of forces." Hence Newton's term for force is vis impressa (Thomson and Tait's Nat. Phil., \$2I 7); though, where there is no room for mistake, he often employs the single word vis.

One of the main objects of my lecture was to protest against the absurd custom of translating the word vis in every case by the scientific word force. It is not easy to get an unobjectionable single word for the purpose, for most of the available words have already a semi-scientific sense attached to them. The word power is very flexible in its meaning, and would have been suitable had it not been already seized by the enoineers. Thus (Thomson and Tait, $\S 216$ ) vis insita is rendered innate power. And, giving the word as wide an application as Newton gives to vis, we might render wis wiza as active power, which is not $\mathrm{fdr}$ from actual or kinetic energy. But this is merely a suggestion.

In Posgendorff's Annalen (No. 7 of this year) Prof. Zollner translates the scientific term, "the perpetual motion," by "die beharrliche Beregzmg," and thus, to his own satisiaction at least, proves me to be ignorant alike of the proper meaning of the Latin perpetuum mobite and of the first law of motion !

In another journal I have lately been held up to scorn, not in the main for any real or imputed fault of mine, but because my would-be critic (Mr. R. A. Proctor) happens not to know the scientific meaning of "absolute" measure!!

I could give many more telling instances, great and small, but I have given enough to show how needful was my contention for definiteness and accuracy.

P. G. TAIT 